\title{
Identity Override: How Sexual Orientation Reduces the Rigidity of Racial Boundaries
}

\author{
Adam L. Horowitz, ${ }^{\text {a,b }}$ Charles J. Gomez ${ }^{\mathrm{c}}$ \\ a) Tel Aviv University; b) Stanford University; c) Queens College, City University of New York
}

\begin{abstract}
Although most Americans have limited interpersonal relations with different-race others, interracial ties are notably more common among gay, lesbian, and bisexual (GLB) individuals. Departing from the modal explanation of intergroup relations theories, which suggests that individual propensities for between-group interactions are driven by demographic groups' physical location relative to one another, we show that, beyond propinquity, GLB interraciality is spiked through active identification as GLB. We evaluate full romantic/sexual partnership histories along with friendship network racial compositions for respondents in a large, nationally representative sample. We show that GLBs have a greater likelihood and frequency than heterosexuals of forming multiple types of interracial ties and also that this effect applies only to those who actively identify as GLB and not to those who engage in same-sex relations but do not identify as GLB. This discovery refines theories of intergroup relations, isolating how identification serves as a mediating mechanism that can heighten the propensity for intergroup interaction. We argue that active identification with a group that crosses racial boundaries spurs overriding the rigidity of intergroup borders that otherwise dissuade interpersonal diversity.
\end{abstract}

Keywords: intergroup relations; race and ethnicity; sexual orientation; heterogamy; homophily; identification

Citation: Horowitz, Adam L., and Charles J. Gomez. 2018. "Identity Override: How Sexual Orientation Reduces the Rigidity of Racial Boundaries." Sociological Science 5: 669-693.

Received: July 3, 2018

Accepted: August 6, 2018

Published: November 7, 2018

Editor(s): Mario Small

DOI: $10.15195 / \mathrm{v} 5 . \mathrm{a} 28$

Copyright: (C) 2018 The Author(s). This open-access article has been published under a Creative Commons Attribution License, which allows unrestricted use, distribution and reproduction, in any form, as long as the original author and source have been credited. (C) (i)
LTHOUGH the last several decades have seen some growth in interracial (i.e., between people of different races) relationships, most relationships in the United States, both romantic and platonic, continue to be intraracial (i.e., between people of the same race; Hallinan and Williams 1987; Kao and Joyner 2004). The extent of relationship interraciality differs between populations, however, including notably high interraciality in gay, lesbian, and bisexual (GLB) romantic partnerships (Jepsen and Jepsen 2002; Rosenfeld and Kim 2005).

The present study examines the nature of this sexual orientation-based disparity in interracial ties. We evaluate respondents in the National Longitudinal Survey of Adolescent to Adult Health (Add Health) to pinpoint the role of actively identifying as GLB in driving interracial relationships. Our analysis shows that GLBs are more likely than heterosexuals to (1) have ever engaged in an interracial sexual or romantic partnership, (2) have had more interracial sexual/romantic partnerships (independent of the total number of relationships), and (3) have more racially diverse friendship networks. By parsing the effects of behavior from those of identification, we discover that only individuals who actively identify as GLB show increased relationship interraciality; the interraciality of those who engage in samesex relationships but do not have active GLB identification remains statistically indistinct from heterosexuals. 
Through this analysis, we expand the empirical understanding of the GLB interraciality phenomenon as well as theoretically advance the study of intergroup relations. Empirically, we extend the scope of existing analyses by considering multiple types of relationships (including cohabiting romantic/sexual partnerships, noncohabiting romantic/sexual partnerships, and friendships) and by examining GLB status with multiple sexual orientation measures (that distinguish between the effects of behavior and of identification). In illuminating the relationship between sexual orientation and interracial ties, we also propel a noteworthy theoretical advance. Existing theoretical accounts explain variation in interraciality by pointing to the location in which individuals are physically situated; we diverge from this standard by showing that, beyond propinquity, GLB interraciality is a matter of identification. Drawing on our findings, we argue that membership in certain social categories makes individuals more susceptible to bypassing interactional borders between people of different demographic groups. If an identity is highly salient, core to how individuals socially locate themselves, and comprised of members who are diverse across lines on which homophily is typically structured, then that identity can aid in overriding the rigidity of intergroup boundaries that typically dissuade interpersonal diversity. For the overriding effect to occur, though, identification with the relevant group must be actively claimed.

\section{Background}

\section{Relationship Interraciality in the United States}

Research increasingly denotes the value of interracial interactions for outcomes such as enhancing problem solving, cultural competence, and general group performance (Herring 2009; Hu and Kuh 2003; Nemeth 1986). Yet in the United States, most relationships, both romantic and platonic, are intraracial (Hallinan and Williams 1987; Kao and Joyner 2004). ${ }^{1}$ Even without the sociopolitical and historical contexts that in the past made interracial relationships taboo-and/or illegal, in some instances-interracial relationships still comprise a rather small portion of relationships today (Rockquemore and Brunsma 2008; Romano 2003). According to a recent Pew Research Center analysis, although the number of interracial marriages more than doubled between 1980 and 2010, the overall rate in the latter was nevertheless just 8.4 percent (Wang 2012).

A line of research sets out to discern why some people are more likely than others to form interracial relationships despite the tendency for limited interracial interaction. This scholarship collectively and consistently points to propinquity, suggesting that a person's physical presence and corresponding engagement in a racially diverse network correlates with a higher likelihood of forming interracial ties (Blau 1977; McPherson, Smith-Lovin, and Cook 2001). Those who live in more racially mixed neighborhoods and attend more heavily diverse schools, for example, are more likely to have friendships with different-race others (Clark-Ibáñez and Felmlee 2004; Perry 2013; Vaquera and Kao 2005) and to date interracially (Carver, Joyner, and Udry 2003; Fujino 1997; Yancey 2002). Because urban areas are, on average, more racially diverse than suburban and rural areas, propinquity 
accounts suggest that living in an urban setting creates an increased propensity for interracial relationships, in comparison to living elsewhere, net of variation in racial demographics (e.g., Johnson and Jacobson 2005; Rosenfeld 2007).

One demographic group that consistently has higher rates of interracial ties is the gay, lesbian, and bisexual (GLB) population. ${ }^{2}$ In particular, scholarship pinpoints an increased tendency for interraciality among cohabiting same-sex couples over married or cohabiting heterosexual couples, as several U.S. Census analyses evidence. Jepsen and Jepsen's (2002) evaluation of the 1990 Census found that belonging to different racial groups reduces the probability of being a prospective couple by 37 percent for married couples but only 12 percent for same-sex male couples. Rosenfeld and Kim (2005) found that cohabiting same-sex couples were significantly more likely to be interracial than married heterosexual couples by a factor of 2.82 in the 1990 Census and a factor of 1.42 in the 2000 Census. Gates (2010a) pegged interraciality among American households in the 2010 Census at 20.6 percent for same-sex couples, 18.3 percent for different-sex unmarried couples, and 9.5 percent different-sex married couples. Although reducing between censuses, the gap in interraciality by sexual orientation has remained statistically significant.

A predominant explanation for heightened GLB interraciality focuses on a logic of numbers: The small size of the GLB population results in a smaller market of people with whom one can enter into a same-sex partnership (Ellingson et al. 2004; Kurdek and Schmitt 1987; Schnoor and Weinfeld 2005; Schwartz and Graf 2009). With fewer partner options, the reasoning goes, it becomes more difficult for any one individual to seek racial homophily. Accordingly, by placing less emphasis on homophilous traits in seeking relationships, GLBs organically become more prone to racial heterogamy (Harris and Ono 2005; Mays, Cochran, and Rhue 1993; Peplau, Cochran, and Mays 1997).

This scarcity argument is entangled with propinquity, particularly through homing in on the effect of living in less densely populated areas. Although interracial ties typically decline as distance from urban centers increases (Marsden 1987), the scarcity argument proposes that the limited availability of same-sex partners in more sparsely populated settings propels rural GLBs into increased partnership interraciality. This may produce pronounced effects for GLBs of racial minority backgrounds: In an already small subpopulation, an even smaller population of racial minority GLBs makes the option for intraracial partnering very limited for minority GLBs. In the combined scarcity and propinquity view, then, even if one might be prone to exclude different-race others in a larger pool of potential options (i.e., as is assumed to be the case for heterosexuals), nonurban GLBs default to partnering with the most conveniently available others also seeking same-sex partners, independent of race.

This argument is demographic, suggesting that the composition of others in a person's physical location dictates with whom they become open to and/or interested in forming relationships (Fujino 1997). In this analysis, we propose that, more than where one is physically located, it is how one socially locates oneself that spurs interraciality. 


\section{Identity Override: A Theoretical Proposition}

A robust literature on ethnic and racial identity provides that shared membership within a group is a powerful source for individuals to develop meaningful connections to one another. This is partially due to a tendency to define groups according to who belongs and who does not (Barth 1969; Wimmer 2013), priming psychological closeness to those who are a part of one's in-group and distance from those who are in an out-group (Tajfel 1981). Sharing in-group membership creates a sense of similarity among members that facilitates seamless interaction and subsequently eases partnering with other group members (Gaertner et al. 1993). Impulses to protect and propagate one's group reduce out-group interactions and underlie attempts to dissuade heterogamy (Surra and Milardo 1991).

Such efforts to dissuade against heterogamy are the basis for the "border patrolling" explanation of why interracial relationships remain relatively limited (Kreager 2008). This explanation suggests that members of racial groups find importance in maintaining distinctive identities and create "borders" around their groups in order to continue maintaining these distinctions from one generation to the next. Although the borders are metaphorical, they are realistically and meaningfully policed. Policing, for example, may take the form of signaling that racial homogamy is more appropriate than heterogamy (Lieberson and Waters 1988; Root 2001), with signals ranging from being subtle (e.g., family providing a cold reception to an individual's different-race significant other) to being direct (e.g., threatening to disown a child who marries interracially; Felmlee 2001).

We suggest that the same conditions that give rise to border patrolling can also serve as the foundation for a mechanism to override racial borders. Although many groups can be a source of individual identity, we claim that some fall into a select cadre that carry particularly robust meanings and enhanced effects on determining social relations. For example, it is well established that members of racial minority groups connect through a confluence of shared social conditions, such as shared minority status and its corresponding political and opportunistic ramifications; spaces that become shared by choice or structure; and a culture that comes to reflect and represent the group and its members (e.g., Cornell and Hartmann 2007). GLB identity functions in a similar fashion. GLB status is a source of social and legal outsiderness, and the literature has shown it to be a salient status characteristic through which people evaluate others (Johnson 1995). GLB status also functions as a collective identity ( $\mathrm{D}^{\prime}$ Emilio 1983) that is central to structuring the development of meaningful relationships (Sherrod and Nardi 1994; Stanley 1996) and that has shared spaces for interaction (Fetner et al. 2012) and a defined shared culture (Herdt 1992; Humphries and Miller 1980; Irvine 1996).

Race and sexual orientation, then, share a particular salience to individual identity because of how they bind members together through a spate of shared conditions. Notably, though, being GLB is a trait that cuts across racial groups. We claim that, although race and sexual orientation are bound together by their salience and robustness for individual identity, the cross-racial nature of GLB membership allows it to override the otherwise high borders between people without such a second salient identity. 
The notion that social categories can intersect in ways that ease relationships between people of different groups is not in itself novel; the idea was well postulated by Simmel (1955) and has been a consistent foundation of noteworthy studies and theories of homophily and heterogamy, most notably those by Blau and his colleagues (Blau 1977; Blau, Beeker, and Fitzpatrick 1984; Blau, Blum, and Schwartz 1982; Blau and Schwartz 1984), who term the phenomenon "cross-cutting." To be sure, we build on the foundation set by this tradition in our approach. Where we diverge, however, is in positing that cross-cutting is a necessary but not sufficient condition to enable a secondary social category to override a primary one.

For Blau and others, propinquity determines the likelihood that a person will be present in cross-cutting scenarios, and it is therefore structural conditions that produce heightened intergroup relations. We argue that cross-cutting is only effective for those who actively identify with a relevant secondary group. To that end, the effect of GLB status on interraciality is a product of the cross-cutting nature of race within sexual orientation but not a function of that intersection alone; heightened interraciality is further dependent on active identification with the sexual minority category. Empirically, the proof of this would lie in the existence of differences between individuals who engage in same-sex partnerships and actively identify as GLB versus individuals who engage in same-sex partnerships but do not identify as GLB, with heightened interraciality over heterosexuals not appearing for the latter set.

The value of our empirical approach is its ability to evaluate this. Because we examine GLB status with multiple measures of sexual orientation, we are able to parse between behavioral and identificational effects of being GLB and therefore to isolate differences in outcomes between those who engage in same-sex relationships with versus without identifying as GLB. Empirical evidence for our proposition would suggest that GLB status reduces the rigidity of racial boundaries across relationship types in correlation with active identification as GLB and would therefore support our theoretical argument that, when it comes to the effect of cross-cutting social categories, active identification with a secondary social category consequentially increases susceptibility to bypassing intergroup boundaries.

\section{Data, Predictions, and Analyses}

\section{Data Set}

We conduct our analysis using the National Longitudinal Survey of Adolescent to Adult Health (Add Health) (Harris et al. 2009). Add Health is a longitudinal survey collecting information on a sample of respondents who were students in grades seven through 12 in 80 U.S. middle and high schools during its first wave in 1994. Survey administrators used a cluster-sampling frame to select a representative set of schools in terms of U.S. region, urbanicity, size, and ethnicity. Administrators stratified students by grade and sex and then randomly selected approximately 17 students from each stratum for interviews. Field interviewers conducted in-school and in-home interviews with participants. 
Earlier analyses of the racial composition of GLB relationships draw on data from U.S. censuses (Jepsen and Jepsen 2002; Rosenfeld and Kim 2005). Census data have the benefit of size and representativeness but are subject to several limitations. Census data are confined only to cohabiting partnerships and current partnerships existing at the time of data collection. Within this snapshot, moreover, the partnership status of two same-sex individuals residing together has often had to be inferred (Gates 2010b; Schwartz and Graf 2009). Though more limited in size, Add Health provides for several analytical enhancements by collecting data on many forms of sexual and romantic partnerships, on all partnerships that respondents have had in their lifetimes, on the racial diversity of respondent friendship networks, and on self-identified sexual orientation.

In the third and fourth waves of the study, respondents' generated lists of all current and prior sexual/romantic partners, gathering information on each partner. Because Add Health determines the race of each respondent as well as the race of each current and previous partner, these data make it possible to assess whether a person was in an interracial partnership at the time of the survey along with whether they have ever been in an interracial partnership and how many of their partnerships have been interracial. Thus, we can determine what proportion of all of each respondent's partnerships have been interracial versus intraracial. Both the third and fourth waves collected complete partnership history information. Correspondingly, the fourth wave includes all partnerships appearing in the third wave plus partnerships since, and we therefore focus our analysis on data from the fourth wave. The fourth wave was conducted in 2008 and 2009, when respondents were between 24 and 32 years old.

\section{Predictions and Variable Construction}

If our identification explanation holds, certain conditions should be met empirically, which we account for in this analysis. First, if GLB status facilitates interracial interaction via shared identity, then we should see similar patterns of interraciality in a broad spectrum of relationships. Beyond the pattern for cohabiting partnerships identified in census analyses, identification should produce an equivalent interraciality in noncohabiting partnerships and should structure relationships beyond those of a romantic/sexual nature (i.e., should produce increased interraciality in friendships).

Accordingly, we evaluate multiple forms of interracial ties as dependent variables. (Henceforth, we refer to all types of interpersonal ties collectively as "relationships" and to those specifically of a sexual and/or romantic nature as "partnerships." We also evaluate "friendships" as a type of platonic tie, though noting that this does not encapsulate all platonic ties, such as those of a professional nature.) Although previous analyses focus on either partnerships or friendships, we leverage Add Health data to consider both in making our case for an active identification-driven effect.

We consider each of 20,318 partnerships reported by 10,281 respondents. ${ }^{3}$ We coded partnerships according to whether the gender and race of a respondent and each partner matched or mismatched. ${ }^{4}$ We then collapsed this to determine each 
respondent's total number of partnerships as well as the total and proportional numbers of same-sex, different-sex, interracial, and intraracial partnerships. For friendship networks, we draw on an Add Health question asking respondents to select which of six categories most closely describes their composition of friends: "all your race," "almost all your race," "mostly your race," "about half your race," "mostly other races," "almost all other races," and "all other races."

Notably, the racial composition of friendship networks by sexual orientation has particularly scant presence in existing literature, presently limited to a series of studies by Galupo and colleagues utilizing pioneering but nonrepresentative surveys (Galupo 2007, 2009; Galupo and Gonzalez 2013). In addition to supporting our theoretical approach, then, nationally representative evidence of GLB friendship interraciality would prove a meaningful empirical contribution to the study of GLB social networks.

Also crucial to our analysis is isolating the results that are indeed related to identification. There are various ways in which both colloquialism and scholarship define sexual orientation and, consequently, multiple approaches to constructing variables measuring GLB status (Black et al. 2000). Plenty of people have had same-sex sexual experiences but do not identify as GLB or participate in a GLB community. If our theory is correct, heightened interraciality is dependent on GLB identity being actively claimed. We account for this by parsing the effect of identification in constructing sexual orientation as an independent variable.

Add Health data allow us to use multiple methods of constructing a GLB variable. We employ two constructions of GLB status. Our first construction bases GLB status on behavior (i.e., whether same-sex partners appear in a respondent's partnership history), wherein GLB status is coded according to whether a respondent has had one or more partnerships with a same-sex partner.

Our second construction combines behavior and identity to isolate the match or mismatch between sexual behavior and active identification. This construction draws on an Add Health question asking respondents to choose which sexual orientation category best describes them, providing the following options: "100 percent heterosexual," "mostly heterosexual," "bisexual," "mostly homosexual," "100 percent homosexual," and "no response." We code those describing themselves as "100 percent homosexual," "mostly homosexual," "bisexual," or "mostly heterosexual" as GLB so as to allow us to isolate a mismatch between behavior and identity in as precise terms as possible (i.e., only coding for a mismatch when an individual with same-sex partnerships identifies as "100 percent heterosexual"). ${ }^{6}$ From this, we create sexual orientation categories that compare three groups of respondents: "heterosexuals" (those who self-identify as 100 percent heterosexual and have had partnerships only with different-sex partners), "GLB identifiers" (those who have had one or more partnerships with a same-sex partner and identify with a GLB sexual orientation category), ${ }^{7}$ and "GLB nonidentifiers" (those who have had one or more partnerships with a same-sex partner but selected "100 percent heterosexual" or "no response" in describing their sexual orientation). ${ }^{8}$

Using these three groups allows us to disentangle the effects that behavior and identification have on the outcomes discerned. If our theory is supported, differences in relationship interraciality should appear when we parse out GLB 
status as a product of both behavior and identification. We predict that those who actively identify as GLB are more likely than heterosexuals to have ever had an interracial partnership, have a higher predicted total number of interracial partnerships, and have a greater proportion of different-race friends. However, those who engage in same-sex partnering but do not actively identify as GLB are not more likely than heterosexuals to have ever had an interracial relationship, have a higher predicted total number of interracial partnerships, nor have a greater proportion of different-race friends.

Finally, we argue that the relationship between GLB identification and interraciality should exist in spite of propinquity conditions. Accordingly, in our models, we give particular attention to the roles that urbanicity and a respondent's race play in order to account for propinquity's effect. Given that propinquity explanations account for GLB interraciality by drawing on the role of urbanicity (i.e., either urban centers encourage interraciality because they are more diverse or rural areas make GLB interraciality a necessity through partner market scarcity), we control for urbanicity to measure the extent to which it drives interraciality outcomes. ${ }^{9}$ We further control for respondent race to address the suggestion that interraciality may be driven by a demographic imperative for minority GLBs (i.e., particularly limited same-race GLB partner options make homophily unrealistic). Combined, these controls create a metric on which we can evaluate propinquity's role.

We additionally control for the total number of sexual partners, gender, U.S. versus foreign birth, and socioeconomic status (measured through personal income and educational attainment) in each model (see descriptive statistics in Table 1 and a correlation matrix of variables in Table 2).

\section{Models}

We analyze the data with three models. Two models evaluate partnerships. We utilize both logistic regression and negative binomial regression models to examine partnerships in distinct ways. The logistic regression (logit) model is an assessment of likelihood, in this case, the likelihood of having ever had an interracial partnership. The negative binomial (NB) regression provides an event count. Used when a dependent variable occurs as a rare event and is measured in nonnegative integers that are limited in range (as applies to an individual respondent's total number of partnerships), NB uses maximum likelihood estimation to predict the expected number of events. Here, the NB model estimates the expected absolute number of interracial partnerships.

What makes comparing partnerships tricky is that a respondent's total number of partnerships influences how frequently the respondent appears to partner interracially. For example, a respondent who has had one different-race partner but only two partners overall would seem to be "more" of an interracial dater than a respondent who has had three different-race partners but nine partners total. We therefore account for the total number of partners in both partnership models. In our logit model, we employ the total number of partnerships as a control. In our NB model, we employ statistical exposure. Exposing the model to respondents' total number of partnerships offsets the numerical estimation by setting the expected 
Table 1: Descriptive statistics for respondents.

\begin{tabular}{|c|c|c|c|c|c|c|}
\hline \multicolumn{5}{|l|}{ Categorical Variables } & Count & Proportion \\
\hline \multicolumn{7}{|c|}{ Sexual Orientation: Behavior Only } \\
\hline Heterosexual & & & & & 9,956 & $96.84 \%$ \\
\hline GLB & & & & & 325 & $3.16 \%$ \\
\hline \multicolumn{7}{|l|}{ Sexual Orientation: Identification } \\
\hline Heterosexual & & & & & 8,797 & $96.44 \%$ \\
\hline GLB Nonidentifiers & & & & & 68 & $0.75 \%$ \\
\hline GLB Identifiers & & & & & 257 & $2.82 \%$ \\
\hline \multicolumn{7}{|l|}{ Race } \\
\hline White & & & & & 5,928 & $57.66 \%$ \\
\hline Black & & & & & 2,018 & $19.63 \%$ \\
\hline Asian & & & & & 609 & $5.92 \%$ \\
\hline Hispanic & & & & & 1,659 & $16.14 \%$ \\
\hline Native American & & & & & 67 & $0.65 \%$ \\
\hline \multicolumn{7}{|l|}{ Urbanicity } \\
\hline Rural & & & & & 1,952 & $18.99 \%$ \\
\hline Suburban & & & & & 4,539 & $44.15 \%$ \\
\hline Urban & & & & & 3,790 & $36.86 \%$ \\
\hline \multicolumn{7}{|l|}{ Sex } \\
\hline Male & & & & & 4,598 & $44.72 \%$ \\
\hline Female & & & & & 5,683 & $55.28 \%$ \\
\hline \multicolumn{7}{|l|}{ Nativity } \\
\hline Non-U.S. Birth & & & & & 652 & $6.34 \%$ \\
\hline U.S. Birth & & & & & 9,629 & $93.66 \%$ \\
\hline \multicolumn{7}{|l|}{ Education } \\
\hline Graduate Degree & & & & & 869 & $8.45 \%$ \\
\hline BA and Some Graduate & & & & & 2,695 & $26.21 \%$ \\
\hline HS or Less than BA & & & & & 6,067 & $59.01 \%$ \\
\hline Less than HS & & & & & 650 & $6.32 \%$ \\
\hline Continuous Variables & $0 \%$ & $25 \%$ & $50 \%$ & $75 \%$ & $100 \%$ & Mean \\
\hline Total Number of Partnerships & 1 & 1 & 1 & 2 & 27 & 1.88 \\
\hline Personal Income (in Dollars) & - & 16,000 & 30,000 & 45,000 & 999,995 & $36,069.65$ \\
\hline
\end{tabular}

Source: National Longitudinal Survey of Adolescent to Adult Health (Add Health) Waves III and IV.

number of interracial partnerships predicted by the model proportionally to the total number of partnerships.

Our third model hones in on the interraciality of respondents' friendship networks utilizing a multinomial logistic regression model. It evaluates a categorical dependent variable by assessing $\mathrm{N}$-minus-one categories in relation to a single, primary reference category. In this model, six friendship network composition categories are assessed in relation to the reference category of having friends who are "all your race." With evaluations made in relation to a reference group for both the dependent and primary independent variables, outcomes reflect two comparisons simultaneously: how likely each friendship network composition category is in comparison to "all your race" for GLBs in comparison to heterosexuals. 


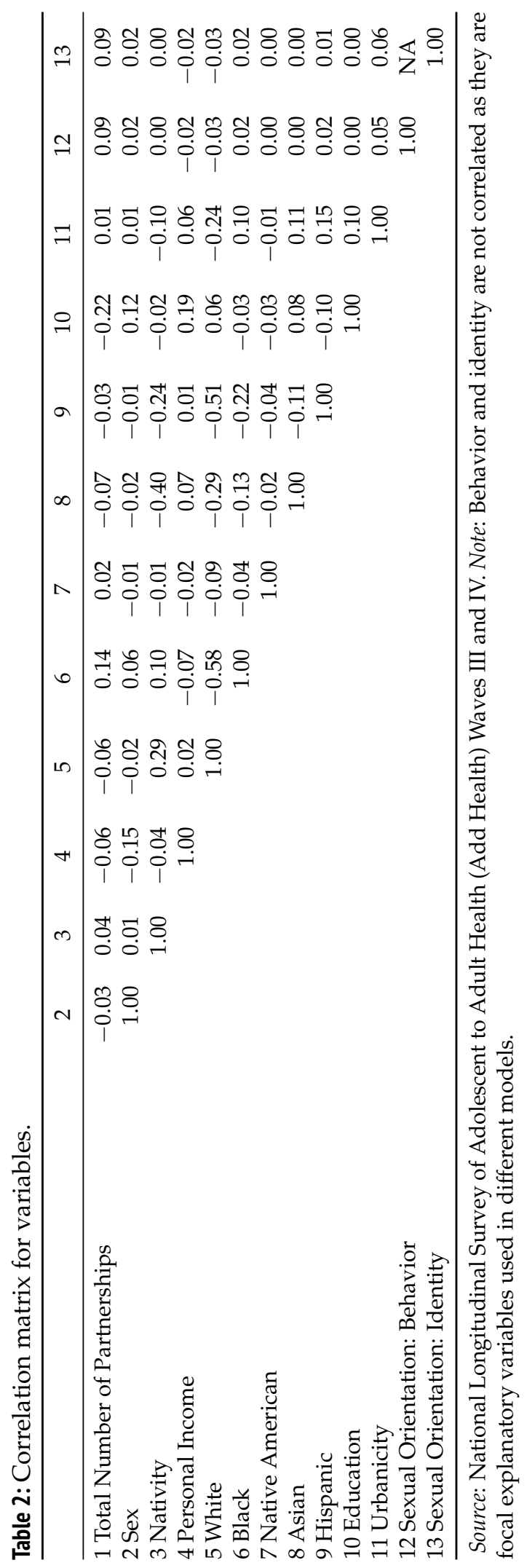


We checked our models for the existence of multicollinearity and heteroscedasticity, with particular attention toward our explanatory variables, finding no corresponding problems. We discuss our results in terms of log-odds, as our focal explanatory variables are dichotomous.

\section{Results}

\section{Partnership Interraciality}

In our first set of analyses, we assess respondent propensities for interracial partnerships. The models in Table 3 compare GLBs directly to heterosexuals when GLB status is measured in terms of behavior (i.e., whether a respondent has had one or more same-sex partnerships). The logit model predicts GLBs to be significantly more likely to have had one or more interracial partnerships than heterosexuals by a factor of $2.12(\{\exp [\beta]\}=\{\exp [0.75]\}=2.12)$. In terms of the estimated number of interracial partners, the NB model predicts GLBs to have 49 percent (i.e., $\exp [0.40]$ $=1.49$ ) more interracial partners on average than heterosexuals.

When sexual orientation is parsed by the match or mismatch between behavior and identity in a second set of models, however, it becomes evident that this effect is not consistent among all those who have had same-sex relationships. The models in Table 4 compare GLB identifiers and GLB nonidentifiers to heterosexuals. In these models, GLB identifiers continue to be significantly more likely than heterosexuals to have had one or more interracial partnerships, by a factor of 2.39 (i.e., $\exp [0.87]=2.39$ ) in the logit model, and their estimated total number of interracial partners continues to be significantly higher than that of heterosexuals, by 65 percent (i.e., $\exp [0.50]=1.65$ ) in the NB model. GLB nonidentifiers, however, are neither significantly more likely to have had one or more interracial partnerships than heterosexuals nor to have a significantly different estimated total number of interracial partnerships.

The estimates in both constructions hold with the control variables in place. The findings here correspond with earlier scholarship on cohabiting partnerships. Yet in expanding the scope of the pattern to myriad sexual/romantic partnerships, our analysis suggests that GLB propensity for interraciality is consistent independent of the type or length of a partnership. The findings also show that partnership interraciality differences are driven by identifying as GLB, providing the first layer of support for our proposed theory.

\section{Friendship Interraciality}

Our next set of analyses examine the effect of sexual orientation on friendship network composition. As with the partnership analyses, we first compare GLBs directly to heterosexuals when GLB status is constructed in terms of behavior alone (Table 5). As with partnerships, when evaluated through behavior alone, all GLBs are more likely than heterosexuals to have more diverse friends. GLBs are estimated to select four of six friendship network composition categories over "all your race" at significantly higher rates than are heterosexuals. GLBs are predicted to select 
Table 3: Logistic regression and negative binomial regression models predicting partnership interraciality by sexual orientation (behavior only).

\begin{tabular}{lcc}
\hline & $\begin{array}{c}\text { Logistic Regression } \\
\text { Model }\end{array}$ & $\begin{array}{c}\text { Negative Binomial } \\
\text { Regression Model }\end{array}$ \\
\hline GLB (Ref: Heterosexual) & $0.75^{\dagger}$ & $0.40^{\dagger}$ \\
& $(0.13$ & $(0.08)$ \\
(Intercept) & $-3.36^{\dagger}$ & $-2.66^{\dagger}$ \\
Control Variables Included? & $(0.14)$ & $(0.10)$ \\
\hline AIC & Yes & Yes \\
BIC & $9,809.06$ & $13,925.51$ \\
Log Likelihood & $9,917.63$ & $14,034.08$ \\
Deviance & $-4,889.53$ & $-6,947.75$ \\
Num. Obs. & $9,779.06$ & $7,101.68$ \\
\hline
\end{tabular}

Source: National Longitudinal Survey of Adolescent to Adult Health (Add Health) Waves III and IV. Notes: Models control for the total number of partnerships, gender, U.S. birth, race of respondent, urbanicity, education, and personal income. The logistic regression model predicts the likelihood of having ever had one or more interracial partnerships (coefficients reported as log odds). Negative binomial regression predicts the expected total number of interracial partnerships (coefficients reported as odds ratios). Standard errors are listed in parentheses.

${ }^{\dagger} p<0.01$ (two-tailed test).

two categories characterizing friendship networks as being comprised of half or a majority of different-race friends-"about half your race" and "mostly other races" - over "all your race" significantly more frequently than heterosexuals by 51 percent $(\exp [0.41]=1.51)$ and 125 percent $(\exp [0.81]=2.25)$, respectively.

Once again, however, the significance of the results is modified when sexual orientation is parsed according to whether behavior and identification match or mismatch (Table 6). When comparing both GLB identifiers and GLB nonidentifiers to heterosexuals, GLB identifiers continue to have significantly higher predicted rates of selecting diversity categories other than "all your race" over heterosexuals, whereas GLB nonidentifiers do not. In fact, versus the behavior-alone analysis, the predicted rates for GLB identifiers are significantly higher for all categories other than "all your race." Magnitudes are also noticeably higher. In this model, the predicted likelihood of selecting "about half your race," "mostly other races," "almost all other races," and "all other races" over the "all your race" for GLB identifiers is 72 percent $(\exp [0.54]=1.72), 216$ percent $(\exp [1.15]=3.16), 156$ percent $(\exp [0.94]$ $=2.56)$, and 144 percent $(\exp [0.89]=2.44)$, respectively, in comparison to heterosexuals. GLB nonidentifiers are not significantly more likely than heterosexuals to choose any category over "all your race."

The estimates in both constructions hold with the control variables in place. These findings show that GLBs are more likely to have more racially diverse friendship networks than heterosexuals. As with partnerships, though, this outcome only applies to those who identify as GLB, further suggesting that active identification is the mechanism driving increased propensity for interracial ties. 
Table 4: Logistic regression and negative binomial regression models predicting partnership interraciality by sexual orientation (behavior-identification match vs. mismatch).

\begin{tabular}{|c|c|c|}
\hline & $\begin{array}{c}\text { Logistic Regression } \\
\text { Model }\end{array}$ & $\begin{array}{l}\text { Negative Binomial } \\
\text { Regression Model }\end{array}$ \\
\hline \multicolumn{3}{|l|}{ Sexual Orientation (Ref: Heterosexuals) } \\
\hline GLB Nonidentifiers & $\begin{array}{c}0.47 \\
(0.29)\end{array}$ & $\begin{array}{c}0.22 \\
(0.17)\end{array}$ \\
\hline GLB Identifiers & $\begin{array}{r}0.87^{\dagger} \\
(0.14)\end{array}$ & $\begin{array}{r}0.50^{\dagger} \\
(0.09)\end{array}$ \\
\hline Total Number of Partnerships & $\begin{array}{r}0.49^{\dagger} \\
(0.02)\end{array}$ & \\
\hline \multicolumn{3}{|l|}{ Race of Respondent (Ref: White) } \\
\hline Black/African American & $\begin{array}{r}0.36^{\dagger} \\
(0.07)\end{array}$ & $\begin{array}{r}0.34^{\dagger} \\
(0.05)\end{array}$ \\
\hline Asian/Pacific Islander & $\begin{array}{r}1.79^{\dagger} \\
(0.11)\end{array}$ & $\begin{array}{r}1.34^{\dagger} \\
(0.08)\end{array}$ \\
\hline Hispanic & $\begin{array}{r}1.62^{\dagger} \\
(0.07)\end{array}$ & $\begin{array}{r}1.19^{\dagger} \\
(0.05)\end{array}$ \\
\hline American Indian/Native Alaskan & $\begin{array}{r}3.06^{\dagger} \\
(0.32)\end{array}$ & $\begin{array}{r}1.82^{\dagger} \\
(0.15)\end{array}$ \\
\hline \multicolumn{3}{|l|}{ Urbanicity (Ref: Rural) } \\
\hline Suburban & $\begin{array}{r}0.44^{\dagger} \\
(0.09)\end{array}$ & $\begin{array}{r}0.29^{+} \\
(0.07)\end{array}$ \\
\hline Urban & $\begin{array}{r}0.52^{+} \\
(0.09)\end{array}$ & $\begin{array}{r}0.32^{+} \\
(0.07)\end{array}$ \\
\hline Female (Ref: Male) & $\begin{array}{r}-0.22^{\dagger} \\
(0.06)\end{array}$ & $\begin{array}{r}-0.14^{+} \\
(0.04)\end{array}$ \\
\hline U.S. Birth (Ref: Non-U.S. Birth) & $\begin{array}{r}0.50^{+} \\
(0.11)\end{array}$ & $\begin{array}{r}0.29^{+} \\
(0.08)\end{array}$ \\
\hline \multicolumn{3}{|l|}{ Education (Ref: Bachelor's Degree) } \\
\hline Graduate Degree & $\begin{array}{c}0.07 \\
(0.11)\end{array}$ & $\begin{array}{c}0.01 \\
(0.09)\end{array}$ \\
\hline High School Degree/Less than Bachelor's & $\begin{array}{r}-0.10 \\
(0.07)\end{array}$ & $\begin{array}{c}0.05 \\
(0.05)\end{array}$ \\
\hline Less than High School & $\begin{array}{r}-0.27^{*} \\
(0.12)\end{array}$ & $\begin{array}{c}-0.02 \\
(0.08)\end{array}$ \\
\hline Personal Income & $\begin{array}{c}0.00 \\
(0.03)\end{array}$ & $\begin{array}{c}-0.01 \\
(0.02)\end{array}$ \\
\hline (Intercept) & $\begin{array}{r}-3.43^{+} \\
(0.15)\end{array}$ & $\begin{array}{r}-2.68^{\dagger} \\
(0.11)\end{array}$ \\
\hline$\overline{\mathrm{AIC}}$ & $8,552.69$ & $12,039.20$ \\
\hline BIC & $8,666.58$ & $12,153.09$ \\
\hline Log Likelihood & $-4,260.34$ & $-6,003.60$ \\
\hline Deviance & $8,520.69$ & $6,180.47$ \\
\hline Num. Obs. & 9,122 & 9,122 \\
\hline
\end{tabular}

Source: National Longitudinal Survey of Adolescent to Adult Health (Add Health) Waves III and IV. Notes: The logistic regression model predicts the likelihood of having ever had one or more interracial partnerships (coefficients reported as log odds). Negative binomial regression predicts the expected total number of interracial partnerships (coefficients reported as odds ratios). Standard errors are listed in parentheses.

${ }^{*} p<0.05,{ }^{\dagger} p<0.01$ (two-tailed tests).

sociological science | www.sociologicalscience.com 
Table 5: Multinomial logistic regression model predicting friendship interraciality by sexual orientation (behavior only; dependent variable reference: "all your race").

\begin{tabular}{lcccccc}
\hline & $\begin{array}{c}\text { Almost all } \\
\text { your race }\end{array}$ & $\begin{array}{c}\text { Mostly } \\
\text { your race }\end{array}$ & $\begin{array}{c}\text { About half } \\
\text { your race }\end{array}$ & $\begin{array}{c}\text { Mostly } \\
\text { other races }\end{array}$ & $\begin{array}{c}\text { Almost all } \\
\text { other races }\end{array}$ & $\begin{array}{c}\text { All } \\
\text { other races }\end{array}$ \\
\hline GLB (Ref: Heterosexual) & $0.41^{*}$ & $0.54^{+}$ & $0.41^{*}$ & $0.81^{\dagger}$ & 0.61 & 0.57 \\
& $(0.17)$ & $(0.17)$ & $(0.18)$ & $(0.23)$ & $(0.33)$ & $(0.31)$ \\
(Intercept) & $-1.17^{\dagger}$ & $-1.62^{+}$ & $-2.17^{+}$ & $-4.01^{+}$ & $-4.55^{\dagger}$ & $-4.68^{\dagger}$ \\
& $(0.17)$ & $(0.18)$ & $(0.18)$ & $(0.26)$ & $(0.36)$ & $(0.33)$ \\
Control Variables Included? & Yes & Yes & Yes & Yes & Yes & Yes \\
\hline
\end{tabular}

Fit statistics: AIC: 30,715.38; BIC: 31,323.38; Log Likelihood -15,273.69; Deviance 30,547.38; Num Obs. 10,281

Source: National Longitudinal Survey of Adolescent to Adult Health (Add Health) Waves III and IV. Notes: Model controls for gender, U.S. birth, race of respondent, urbanicity, education, and personal income. Coefficients are reported as log odds. Standard errors are listed in parentheses.

${ }^{*} p<0.05,{ }^{\dagger} p<0.01$

\section{Does Propinquity Matter?}

In each analysis, we tested the results with numerous combinations of control variables (including the analyses in Tables 3 and 5, in which control variables are not shown). The statistical significance of all outcomes was consistent independent of which control variables were included in the model. Notably, this includes our controls for urbanicity and respondent race, the control variables we use as proxies for propinquity and scarcity, to which we now turn our attention.

Our analyses do not disconfirm the effect of urbanicity predicted in propinquitybased theories of interraciality. With regard to partnerships, respondents in urban and suburban settings are statistically more likely to have had one or more interracial relationships than respondents in rural settings (by factors of $1.62[\exp (0.48)$ $=1.62]$ and $1.55[\exp (0.44)=1.55]$, respectively) as well as to have had 38 percent $(\exp [0.32]=1.38)$ and 34 percent $(\exp [0.29]=1.34)$ more interracial partners on average, respectively (Table 4). With regard to friendships, respondents in urban and rural settings are statistically more likely to select all of the friendship composition categories other than "all your race" than those in rural settings (Table 6).

Similarly, as the literature would predict, racial minority respondents are also statistically more likely to have more interracial relationships than whites. Black, Asian, Hispanic, and American Indian respondents are all significantly more likely to have had one or more interracial relationships and also have a significantly higher estimated overall number of interracial relationships counts. Black, Asian, and Hispanic respondents are statistically more likely than white respondents to select all of the friendship composition categories other than "all your race," whereas American Indian respondents are statistically more likely than whites to do so for the "about half your race," "mostly other races," "almost all other races," and "all other races" categories.

That these results are consistent with prior research is logical given that heterosexuals comprise the large majority of the sample, and the results should be taken 
Table 6: Multinomial logistic regression model predicting friendship interraciality by sexual orientation (behavior-identification match vs. mismatch; dependent variable reference: "all your race").

\begin{tabular}{|c|c|c|c|c|c|c|}
\hline & $\begin{array}{l}\text { Almost all } \\
\text { your race }\end{array}$ & $\begin{array}{l}\text { Mostly } \\
\text { your race }\end{array}$ & $\begin{array}{l}\text { About half } \\
\text { your race }\end{array}$ & $\begin{array}{l}\text { Mostly } \\
\text { other races }\end{array}$ & $\begin{array}{l}\text { Almost all } \\
\text { other races }\end{array}$ & $\begin{array}{c}\text { All } \\
\text { other races }\end{array}$ \\
\hline \multicolumn{7}{|l|}{$\begin{array}{l}\text { Sexual Orientation } \\
\text { (Ref: Heterosexual) }\end{array}$} \\
\hline GLB Nonidentifiers & $\begin{array}{c}0.07 \\
(0.36)\end{array}$ & $\begin{array}{c}0.49 \\
(0.34)\end{array}$ & $\begin{array}{c}0.21 \\
(0.37)\end{array}$ & $\begin{array}{c}-0.58 \\
(0.75)\end{array}$ & $\begin{array}{c}-0.54 \\
(1.04)\end{array}$ & $\begin{array}{c}-0.84 \\
(1.04)\end{array}$ \\
\hline GLB Identifiers & $\begin{array}{r}0.55^{\dagger} \\
(0.19)\end{array}$ & $\begin{array}{r}0.65^{\dagger} \\
(0.19)\end{array}$ & $\begin{array}{r}0.54^{\dagger} \\
(0.20)\end{array}$ & $\begin{array}{r}1.15^{\dagger} \\
(0.25)\end{array}$ & $\begin{array}{r}0.94^{\dagger} \\
(0.35)\end{array}$ & $\begin{array}{r}0.89^{\dagger} \\
(0.33)\end{array}$ \\
\hline \multicolumn{7}{|l|}{$\begin{array}{l}\text { Race of Respondent } \\
\text { (Ref: White) }\end{array}$} \\
\hline Black/African Am. & $\begin{array}{r}-0.52^{\dagger} \\
(0.08)\end{array}$ & $\begin{array}{r}-0.33^{\dagger} \\
(0.09)\end{array}$ & $\begin{array}{r}0.25^{\dagger} \\
(0.08)\end{array}$ & $\begin{array}{r}0.84^{\dagger} \\
(0.15)\end{array}$ & $\begin{array}{r}0.95^{\dagger} \\
(0.23)\end{array}$ & $\begin{array}{r}0.51^{\dagger} \\
(0.20)\end{array}$ \\
\hline Asian/Pacific Islander & $\begin{array}{r}0.53^{\dagger} \\
(0.18)\end{array}$ & $\begin{array}{r}1.28^{\dagger} \\
(0.17)\end{array}$ & $\begin{array}{r}1.73^{\dagger} \\
(0.17)\end{array}$ & $\begin{array}{r}3.33^{\dagger} \\
(0.20)\end{array}$ & $\begin{array}{r}3.41^{\dagger} \\
(0.27)\end{array}$ & $\begin{array}{r}3.20^{\dagger} \\
(0.24)\end{array}$ \\
\hline Hispanic & $\begin{array}{r}0.28^{\dagger} \\
(0.10)\end{array}$ & $\begin{array}{r}0.46^{\dagger} \\
(0.10)\end{array}$ & $\begin{array}{r}1.08^{\dagger} \\
(0.10)\end{array}$ & $\begin{array}{r}2.11^{+} \\
(0.15)\end{array}$ & $\begin{array}{r}2.48^{\dagger} \\
(0.21)\end{array}$ & $\begin{array}{r}1.97^{+} \\
(0.18)\end{array}$ \\
\hline $\begin{array}{l}\text { Am. Indian / Native } \\
\text { Alaskan }\end{array}$ & $\begin{array}{c}0.22 \\
(0.46)\end{array}$ & $\begin{array}{c}0.52 \\
(0.46)\end{array}$ & $\begin{array}{r}0.99^{*} \\
(0.42)\end{array}$ & $\begin{array}{r}2.67^{+} \\
(0.45)\end{array}$ & $\begin{array}{r}3.10^{+} \\
(0.54)\end{array}$ & $\begin{array}{r}2.64^{+} \\
(0.50)\end{array}$ \\
\hline \multicolumn{7}{|l|}{ Urbanicity (Ref: Rural) } \\
\hline Suburban & $\begin{array}{r}0.54^{+} \\
(0.09)\end{array}$ & $\begin{array}{r}0.54^{\dagger} \\
(0.09)\end{array}$ & $\begin{array}{r}0.43^{+} \\
(0.10)\end{array}$ & $\begin{array}{r}0.46^{*} \\
(0.19)\end{array}$ & $\begin{array}{r}0.65^{*} \\
(0.28)\end{array}$ & $\begin{array}{r}0.51^{*} \\
(0.23)\end{array}$ \\
\hline Urban & $\begin{array}{r}0.60^{+} \\
(0.09)\end{array}$ & $\begin{array}{c}0.64^{+} \\
(0.10)\end{array}$ & $\begin{array}{c}0.53^{+} \\
(0.10)\end{array}$ & $\begin{array}{r}0.70^{+} \\
(0.19)\end{array}$ & $\begin{array}{r}0.78^{\dagger} \\
(0.28)\end{array}$ & $\begin{array}{r}0.82^{+} \\
(0.23)\end{array}$ \\
\hline Female (Ref: Male) & $\begin{array}{r}-0.13^{*} \\
(0.06)\end{array}$ & $\begin{array}{r}-0.40^{\dagger} \\
(0.07)\end{array}$ & $\begin{array}{r}-0.43^{\dagger} \\
(0.07)\end{array}$ & $\begin{array}{r}-0.38^{+} \\
(0.11)\end{array}$ & $\begin{array}{r}-0.69^{+} \\
(0.15)\end{array}$ & $\begin{array}{r}-0.54^{+} \\
(0.13)\end{array}$ \\
\hline $\begin{array}{l}\text { U.S. Birth } \\
\text { (Ref: Non-U.S. Birth) }\end{array}$ & $\begin{array}{c}0.19 \\
(0.15)\end{array}$ & $\begin{array}{r}0.42^{\dagger} \\
(0.16)\end{array}$ & $\begin{array}{r}0.40^{+} \\
(0.15)\end{array}$ & $\begin{array}{r}0.53^{\dagger} \\
(0.18)\end{array}$ & $\begin{array}{c}0.22 \\
(0.22)\end{array}$ & $\begin{array}{r}0.70^{+} \\
(0.23)\end{array}$ \\
\hline Education (Ref: B.A). & & & & & & \\
\hline Graduate Degree & $\begin{array}{c}0.23^{*} \\
(0.11)\end{array}$ & $\begin{array}{c}0.10 \\
(0.12)\end{array}$ & $\begin{array}{r}0.37^{+} \\
(0.13)\end{array}$ & $\begin{array}{c}-0.01 \\
(0.22)\end{array}$ & $\begin{array}{c}-0.04 \\
(0.30)\end{array}$ & $\begin{array}{c}-0.13 \\
(0.33)\end{array}$ \\
\hline High School \& < B.A. & $\begin{array}{r}-0.32^{+} \\
(0.07)\end{array}$ & $\begin{array}{r}-0.32^{+} \\
(0.08)\end{array}$ & $\begin{array}{r}0.17^{*} \\
(0.08)\end{array}$ & $\begin{array}{c}0.05 \\
(0.13)\end{array}$ & $\begin{array}{c}-0.14 \\
(0.17)\end{array}$ & $\begin{array}{r}0.48^{+} \\
(0.17)\end{array}$ \\
\hline Less than High School & $\begin{array}{r}-0.52^{+} \\
(0.14)\end{array}$ & $\begin{array}{r}-0.58^{+} \\
(0.15)\end{array}$ & $\begin{array}{c}-0.02 \\
(0.15)\end{array}$ & $\begin{array}{r}-0.66^{*} \\
(0.28)\end{array}$ & $\begin{array}{c}-0.62 \\
(0.35)\end{array}$ & $\begin{array}{c}0.34 \\
(0.28)\end{array}$ \\
\hline Personal Income & $\begin{array}{c}0.02 \\
(0.03)\end{array}$ & $\begin{array}{c}-0.01 \\
(0.04)\end{array}$ & $\begin{array}{c}0.05 \\
(0.03)\end{array}$ & $\begin{array}{r}0.10^{\dagger} \\
(0.04)\end{array}$ & $\begin{array}{c}-0.05 \\
(0.10)\end{array}$ & $\begin{array}{c}0.08 \\
(0.05)\end{array}$ \\
\hline (Intercept) & $\begin{array}{r}-1.27^{\dagger} \\
(0.18)\end{array}$ & $\begin{array}{r}-1.67^{\dagger} \\
(0.19)\end{array}$ & $\begin{array}{r}-2.18^{+} \\
(0.19)\end{array}$ & $\begin{array}{r}-4.04^{+} \\
(0.28)\end{array}$ & $\begin{array}{r}-4.49^{\dagger} \\
(0.38)\end{array}$ & $\begin{array}{r}-4.86^{+} \\
(0.35)\end{array}$ \\
\hline
\end{tabular}

Fit Statistics: AIC: 27,098.31; BIC: 27,738.97; Log Likelihood: -13,459.15; Deviance: 26,918.31; Num. Obs.: 9,122

Source: National Longitudinal Survey of Adolescent to Adult Health (Add Health) Waves III and IV. Notes: Coefficients are reported as log odds. Standard errors are listed in parentheses.

${ }^{*} p<0.05,{ }^{+} p<0.01$ (two-tailed tests). 
as affirming the relevance of propinquity conditions in structuring heterosexual interracial ties. Importantly, nevertheless, controlling for these factors in the models does not change the outcome of the dependent variable in either model. What can be garnered is that GLBs continue to be more likely than heterosexuals to form interracial ties independent of where they live, suggesting that it is not merely urbanicity that drives the outcomes here.

The results further suggest that GLB interraciality this is not a function of scarcity. If racial borders are more permeable among GLBs because of a so-called "beggars market," in which individuals must form relationships with whichever same-sex partner is available in a limited pool (Harris and Ono 2005; Mays et al. 1993; Peplau et al. 1997), then we should expect the interraciality of GLB nonidentifiers to match that of GLB identifiers. That the outcome applies only to GLB identifiers shows that this is not the case, however. People who have had same-sex relationships but do not identify as GLB are statistically no more likely than those who have never had a same-sex relationship to have had an interracial partner.

Although propinquity and scarcity matter, they do not sufficiently explain why GLBs have a higher propensity for relationship interraciality than heterosexuals. Instead, our analysis shows that interraciality outcomes apply to people who actively identify as GLB and not to those who engage in same-sex relationships but do not claim GLB identity, providing clear support for the importance of identification to GLB interraciality.

\section{Discussion and Conclusion}

The findings collectively show that active identification as gay, lesbian, or bisexual increases one's propensity for interraciality in a range of interpersonal relationships in comparison with heterosexuals. This increase does not apply to those who engage in same-sex partnerships without identifying as GLB. Through these findings, this study supports several empirical and theoretical advances.

Empirically, our findings provide new insight into the relationship between sexual orientation and interracial relationships. Expanding on census analyses that tracked cohabiting partnerships existing at the time of data collection, we show that GLBs' pattern of heightened relationship interraciality applies to a full scope of partnerships. By evaluating interraciality in terms of both likelihood of having ever had an interracial partnership and the predicted number of interracial partnerships (after factoring in the total number of partnerships overall), we evince the robustness of GLB interraciality in partnerships. We further provide original, nationally representative evidence of GLB interraciality in friendships and thereby show that GLB propensity for interraciality spans a breadth of relationship types. We believe that this stands as the strongest evidence to date that GLBs have more interpersonal interracial ties of all types than heterosexuals.

Our empirics further make clear that identifying as GLB is associated with different outcomes as a matter of behavior versus claimed identity. By utilizing and parsing between behavioral and identificational measures of sexual orientation, we identify a consequential component of GLB interraciality: GLBs are more likely to have more racially diverse ties than heterosexuals in numerous types of 
relationships and in both urban and nonurban locations but only when they actively identify as GLB. Through this empirical contribution, we advance theoretical perspectives on intergroup relations.

Existing explanations suggest that GLB interraciality is a product of propinquity: GLBs have greater relationship interraciality either because (1) they are more likely to situate themselves in diverse urban contexts or (2) they live in sparsely populated areas with limited options for same-sex partners and must subsequently reduce the extent to which they use race as a discerning factor for forming relationships (Kurdek and Schmitt 1987; Peplau et al. 1997; Rosenfeld and Kim 2005; Schnoor and Weinfeld 2005; Schwartz and Graf 2009). To be sure, matching populationwide trends identified in prior scholarship (Johnson and Jacobson 2005; Qian and Lichter 2007; Yancey 2002), our analysis indeed affirms that there is greater relationship interraciality in urban centers, generally, and that some racial groups have greater propensities for interraciality than others. Our analysis also shows, however, that the effect of sexual orientation on interraciality remains statistically significant even when propinquity variables are controlled, suggesting that propinquity is not sufficiently explanatory as a causal mechanism.

In championing propinquity as the factor that determines the arenas in which conditions leading to heterogamy are more likely to be present, the tradition of Blau and others (Blau 1977; Blau et al. 1982; Blau et al. 1984; Blau and Schwartz 1984) suggests that structural conditions produce heightened intergroup relations. We diverge from and advance this tradition by illuminating that structural conditions, although relevant, are not alone sufficient to activate the cross-cutting phenomenon. In showing the diverging patterns of relationship interraciality among GLB identifiers and GLB nonidentifiers, we more broadly show that a more agentic choice to identify with a group conditions their willingness to bypass social boundaries. Although we characterize this approach in considering sexual orientation and race here, we suggest that our propositions about active identification can more broadly explain how and why identifying with some social categories can override the typical borders existing among the subcategories of another.

As a matter of postulation, we believe that the mechanism underlying the identity override effect is the role of culture in defining groups and social relations. Both race and sexual orientation are subject to social conditions that make them a source of shared outsider status and collective identity. Of consequence, though, is that sexual orientation does this for a collective that is inhabited by people of different races. We believe that it is through sharing culture and status that GLBs of different races have a basis on which to create meaningful relationships with others who share their GLB identity, which is why active identification is of such importance.

Of course, this explanation is outside the scope of the analysis enabled by the data and is therefore limited to postulation. And to be sure, our analysis is subject to several additional limitations. One such limitation is our use of data drawn from an age-restricted sample. We believe there are benefits to honing in on such a sample, notably that the participants came of age in an era of similar political and social mores (at least on the national level). But we also recognize that it is relevant to decipher whether the pattern we identify occurs between age groups. 
The analysis is additionally limited in its ability to establish causality. For instance, a competing explanation may point to the interaction between ideology, location, and sexual orientation. To be sure, a person's presence in a diverse physical location can be the result either of happenstance or purposeful relocation (Fujino 1997; Rosenfeld 2007; Yancey 2002). Rosenfeld (2007), in particular, posits that although those who already live in urban places are more likely to pursue either interracial or same-sex partnerships (because of these partnership types' increased social acceptability in urban centers), it is also the case that those who are more likely to engage in interracial (e.g., because they are more liberal) or same-sex (e.g., because they want to comfortably live as openly GLB) partnerships may be particularly likely to relocate to cities. One causal possibility, accordingly, might suggest that those who are more liberal partner interracially more frequently; that GLBs tend to be more liberal; and, hence, that urban and nonurban GLBs behave similarly due to similar ideology.

To that end, the effect of living in an urban place may be different than we believe it to be. Our analysis addresses the effect of the size of the GLB partner market by controlling for urbanity; an alternative read of the scarcity postulate, however, might suggest the outcome here is influenced by sparseness independent of location. That is, GLB partnering options could be limited even for those in urban locales due to the smaller size of the GLB population relative to that of heterosexuals, making higher GLB interraciality stem from availability in the partner market in any location. In our estimation, threshold matters here: Although partner options are lower for GLBs than heterosexuals in urban locales, they are generally sufficiently high as to meet a numerical threshold wherein GLB individuals can engage in a partner selection process (i.e., dating) not dissimilar to that of heterosexuals. This is less likely to be true in rural environs. Nevertheless, our analysis would ideally test and eliminate the alternative hypothesis. One test, for instance, would be to compare interraciality between GLB identifiers and nonidentifiers according to the size of the GLB populations where they live. Because our data do not provide sufficiently specific information so as to conduct such an analysis, however, our ability to rule out this alternative hypothesis remains a limitation of this study.

Importantly, our account is not intended to suggest (and we do not claim) that any secondary identity can diminish intergroup borders. Technically, of course, heterosexuality is also a group that is transracial. Rather than suggesting that GLB groupness is more transracial than heterosexuality, our approach proposes that racial differences are more meaningfully salient in the former group than the latter. We claim that heterosexuality is so ingrained as the norm in American society that it is rarely a very active part of an individual's identity. Conversely, the shared conditions of historical minority status, spaces, and culture make being GLB a more salient, core component of identity. Because GLBs actively group together on the basis of sexual orientation, and because being GLB is a characteristic that exists between racial groups, GLB identity facilitates the development of interracial ties more readily than heterosexual identity. This compensates for borders that may otherwise prevent meaningful interaction along the lines of another, differing characteristic (e.g., race). We claim that GLB identity is an adequate "replacement" identity through which relationships are developed because it functions similarly 
to race in structuring interpersonal relations and demographically cuts across racial divisions.

Our analysis and theoretical proposition are also not intended to suggest that there is an absence of racism in GLB relationships or communities. To be sure, evidence of precisely that is well documented (e.g., Robinson 2015). Nor do we intend to argue that identifying with a secondary identity can totally erase otherwise socially relevant between-group divisions (i.e., entirely remove racism from GLB communities); certainly, the relationship between sexual orientation and race (and gender) is an important area of study within the growing literature on intersectionality (e.g., Bowleg et al. 2003; McCall 2005). Instead, our findings show how a secondary identity can reduce such divisions.

The identity override approach suggests that active identification with a highsalience, cross-cutting secondary social category produces a pronounced reduction of the borders that otherwise discourage intergroup interaction. In depicting how active identification eases relationship heterogamy (independent of structural conditions, such as propinquity), the identity override approach has further value for evaluating how group-based identities can promote ties between people of different races as well as intergroup boundaries more generally. Salient, culture-based minority identities, we argue, can ease overriding the rigidity of intergroup boundaries and increase interpersonal diversity.

\section{Notes}

1 Constructionist literature debates the definitions of "race" and "ethnicity" and the extent to which these should be treated jointly or separately as categorical constructs (BonillaSilva 1999; Loveman 1999; Wimmer 2015; Winant 2015). Particularly given our departure from the U.S. administrative definition of race-per Office of Management and Budget Directive 15 (Snipp 2003) - by including Hispanic background as a category of analysis, the term "ethnoracial" may better reflect the phenomenon on which we focus. Although noting this, we nevertheless primarily use the term "race" in this analysis in order to match its general predominance in scholarship on intergroup relationships.

2 Gay rights organizations typically use the acronym LGBT (lesbian, gay, bisexual, and transgender) as a descriptor of a broad sexual orientation minority group. We do not include an analysis of transgender individuals in this study because of the difficulty of accurately identifying transgender individuals in survey data and accordingly limit our assessment to GLB individuals.

3 Add Health's third and fourth waves together collect data on 15,701 respondents. Our analysis is limited to 10,281 of these respondents. Because we rely on combined data from both waves, we do not consider respondents with data missing from one or both waves (i.e., 2,588 respondents). We removed smaller numbers of cases for respondents who reported never having had a sexual/romantic partnership and/or who provided unusable responses (e.g., providing an answer of "refused" or "don't know" for gender). We discuss considerations with regard to race, sexual orientation, and urbanicity variables.

4 The gender and race of respondents and partners are reported by each respondent. The race of a respondent is merged from self-reported data in Add Health Wave III. For this analysis, we include Hispanicity in coding for race in accordance with emerging survey 
practices that represent the socially predominant preference for considering Hispanic as a racial background (Pew Research Center 2015). We do not include respondents who identify with more than one race (i.e., 483 cases) in the analyses on which we report here due to the complexity of appropriately coding multiracial respondents' relationships as interracial or intraracial, as is general practice in in the racial heterogamy literature (e.g., Vaquera and Kao 2005). As a precaution, however, we ran sensitivity analyses in which we included respondents who identified with more than one race; our results remained unfazed by this inclusion.

5 Notably, earlier Add Health waves use data on student networks within schools to evaluate interracial ties. We do not rely on these data because respondents were well beyond secondary education age at the time of Add Health Wave IV (99 percent of respondents were born between 1975 and 1982, making the typical years of high school graduation for respondents 1993-2000. Wave IV data were collected 2008-2009).

6 As a robustness check, we constructed an alternative sexual orientation classification that included those selecting "mostly heterosexual" in the heterosexual category. We reran all of our models with this alternative reclassification. The results of this scenario mimic those reported in the main text. Additionally, we attended to the possibility that sexual experimentation may produce instances in which having ever had a same-sex partner may inaccurately reflect the sexual orientation of individuals whose heterosexual orientation otherwise matches their partnering behavior. To account for this, we reran all of the models with two alternative scenarios: (1) only classifying respondents who have had at least two same-sex partners as GLB by behavior and (2) only considering each respondent's two most recent relationships. Each of these scenarios produced results that are consistent with those we present in the text.

7 The disparity in the size of the GLB population between behavior-only and combined behavior-and-identity constructions of sexual orientation aligns with the analysis of Savin-Williams and Ream (2007). This analysis does not combine behavior and identity, but its isolation of these separately affirms the approximate size of the difference between the number of respondents who actively state identifying as GLB and those who have had sexual interactions with either those of the same sex only or with those of a different sex. Gates (2011) further affirms that among Americans more generally, more individuals have engaged in same-sex behavior than identify as GLB.

8 We incorporate respondents who provide "no response" to the sexual orientation question into the GLB nonidentifiers category (i.e., individuals who have engaged in same-sex partnerships but elect not to actively identify as GLB). We do not include those who have had all different-sex partnerships but provide "no response" because we do not construct a "heterosexual nonidentifiers" category for this analysis. Notably, this accounts for the drop in sample size between our behavior-only and combined behavior-and-identity constructions of sexual orientation.

9 Add Health interviews were conducted in interviewees' homes. After completing interviews, interviewers recorded information about the interview location, including its urbanicity. Urbanicity was not reported in 1,157 cases. We accordingly dropped these respondents from the analyses reported but also ran a sensitivity analysis that includes these respondents. In the sensitivity analysis, missing urbanicity did not change the overall results presented in the main text. 


\section{References}

Barth, Frederik. 1969. "Introduction." Pp. 9-38 in Ethnic Groups and Boundaries: The Social Organization of Culture Difference, edited by F. Barth. Prospect Heights, IL: Waveland Press, Inc.

Black, Dan, Gary Gates, Seth Sanders, and Lowell Taylor. 2000. “Demographics of the Gay and Lesbian Population in the United States. Evidence from Systematic Data Sources." Demography 37:139-54. https : //doi .org/10.2307/2648117.

Blau, Peter M. 1977. Inequality and Heterogeneity: A Primitive Theory of Social Structure. New York, NY: Free Press.

Blau, Peter M., and Joseph E. Schwartz. 1984. Crosscutting Social Circles: Testing a Macrostructural Theory of Intergroup Relations. Orlando, FL: Academic Press.

Blau, Peter M., Carolyn Beeker, and Kevin M. Fitzpatrick. 1984. "Intersecting Social Affiliations and Intermarriage." Social Forces 62:585-606. https://doi .org/10.1093/sf/62.3. 585.

Blau, Peter M., Terry C. Blum, and Joseph E. Schwartz. 1982. “Heterogeneity and Intermarriage." American Sociological Review 47:45-62. https : //doi .org/10. 2307/2095041.

Bonilla-Silva, Eduardo. 1999. “The Essential Social Fact of Race.” American Sociological Review 64:899-906. https://doi .org/10.2307/2657410.

Bowleg, Lisa, Jennifer Huang, Kelly Brooks, Amy Black, and Gary Burkholder. 2003. "Triple Jeopardy and Beyond: Multiple Minority Stress and Resiliance among Black Lesbians." Journal of Lesbian Studies 7:87-108. https://doi .org/10.1300/J155v07n04_06.

Carver, Karen, Kara Joyner, and J. Richard Udry. 2003. "National Estimates of Adolescent Romantic Relationships." Pp. 23-56 in Adolescent Romantic Relations and Sexual Behavior: Theory, Research, and Practical Implications, edited by P. Florsheim. Mahwah, NJ: Erlbaum.

Clark-Ibáñez, Marisol, and Diane Felmlee. 2004. “Interethnic Relationships: The Role of Social Network Diversity." Journal of Marriage and Family 66:293-305. https : //doi . org/ 10.1111/j.1741-3737.2004.00021.x.

Cornell, Stephen E., and Douglas Hartmann. 2007. Ethnicity and Race: Making Identities in a Changing World. 2nd ed. Thousand Oaks, CA: Pine Forge Press.

D'Emilio, John. 1983. Sexual Politics, Sexual Communities: The Making of a Homosexual Minority in the United States, 1940-1970. Chicago, IL: University of Chicago Press.

Ellingson, Stephen, Edward O. Laumann, Anthony Paik, and Jenna Mahay. 2004. “The Theory of Sex Markets." Pp. 3-38 in The Sexual Organization of the City, edited by E. O. Laumann, S. Ellingson, J. Mahay, A. Paik, and Y. Youm. Chicago, IL: University of Chicago Press. https://doi.org/10.7208/chicago/9780226470337.003.0001.

Felmlee, Diane H. 2001. "No Couple Is an Island: A Social Network Perspective on Dyadic Stability." Social Forces 79:1259-87. https://doi .org/10.1353/sof .2001.0039.

Fetner, Tina, Athena Elafros, Sandra Bortolin, and Coralee Drechsler. 2012. "Safe Spaces: Gay-Straight Alliances in High Schools." Canadian Review of Sociology 49:188-207. https : //doi.org/10.1111/j.1755-618X.2011.01290.x.

Fujino, Diane C. 1997. “The Rates, Patterns and Reasons for Forming Heterosexual Interracial Dating Relationships among Asian Americans." Journal of Social and Personal Relationships 14:809-28. https://doi.org/10.1177/0265407597146006.

Gaertner, Samuel L., John F. Dovidio, Phyllis A. Anastasio, Betty A. Bachman, and Mary C. Rust. 1993. "The Common Ingroup Identity Model: Recategorization and the Reduction 
of Intergroup Bias." European Review of Social Psychology 4:1-26. https ://doi .org/10. 1080/14792779343000004.

Galupo, M. Paz. 2007. "Friendship Patterns of Sexual Minority Individuals in Adulthood." Journal of Social and Personal Relationships 24:139-51. https ://doi .org/10.1177/ 0265407506070480.

Galupo, M. Paz. 2009. “Cross-Category Friendship Patterns: Comparison of Heterosexual and Sexual Minority Adults." Journal of Social and Personal Relationships 26:811-31. https: //doi.org/10.1177/0265407509345651.

Galupo, M. Paz, and Kirsten A. Gonzalez. 2013. “Friendship Values and Cross-Category Friendships: Understanding Adult Friendship Patterns across Gender, Sexual Orientation and Race." Sex Roles 68:779-90. https://doi .org/10.1007/s11199-012-0211-x.

Gates, Gary J. 2010a. Same-Sex Couples in Census 2010: Race and Ethnicity. Los Angeles, CA: The Williams Institute.

Gates, Gary J. 2010b. Same-Sex Couples in US Census Bureau Data: Who Gets Counted and Why. Los Angeles, CA: The Williams Institute.

Gates, Gary J. 2011. How Many People Are Lesbian, Gay, Bisexual, and Transgender? Los Angeles, CA: The Williams Institute.

Hallinan, Maureen T., and Richard A. Williams. 1987. “The Stability of Students' Interracial Friendships." American Sociological Review 52:653-64. https://doi .org/10.2307/ 2095601.

Harris, David R., and Hiromi Ono. 2005. “How Many Interracial Marriages Would There Be If All Groups Were of Equal Size in All Places? A New Look at National Estimates of Interracial Marriage." Social Science Research 34:236-51. https ://doi .org/10.1016/j . ssresearch.2004.01.002.

Harris, K. M., C. T. Halpern, E. Whitsel, J. Hussey, J. Tabor, P. Entzel, and J. R. Udry. 2009. “The National Longitudinal Study of Adolescent to Adult Health: Research Design." Retrieved December 16, 2015 (http: //www . cpc . unc . edu/projects/addhealth/design).

Herdt, Gilbert H. 1992. Gay Culture in America: Essays from the Field. Boston, MA: Beacon Press.

Herring, Cedric. 2009. "Does Diversity Pay?: Race, Gender, and the Business Case for Diversity." American Sociological Review 74:208-24. https://doi.org/10.1177/ 000312240907400203.

$\mathrm{Hu}$, Shouping, and George D. Kuh. 2003. “Diversity Experiences and College Student Learning and Personal Development." Journal of College Student Development 44:320-34. https://doi.org/10.1353/csd.2003.0026.

Humphries, Laud, and Brian Miller. 1980. “Identities in the Emerging Gay Culture." Pp. 142-56 in Homosexual Behavior: A Modern Reappraisal, edited by J. Marmor. New York, NY: Basic Books.

Irvine, Janice M. 1996. "A Place in the Rainbow: Theorizing Lesbian and Gay Culture.” Pp. 213-38 in Queer Theory/Sociology, edited by S. Seidman. Cambridge, MA: Blackwell.

Jepsen, Lisa K., and Christopher A. Jepsen. 2002. "An Empirical Analysis of the Matching Patterns of Same-Sex and Opposite-Sex Couples." Demography 39:435-53. https://doi . org/10.1353/dem.2002.0027.

Johnson, Bryan R., and Cardell K. Jacobson. 2005. “Contact in Context: An Examination of Social Settings on Whites' Attitudes toward Interracial Marriage." Social Psychology Quarterly 68:387-99. https://doi.org/10.1177/019027250506800406. 
Johnson, Cathryn. 1995. "Sexual Orientation As a Diffuse Status Characteristic: Implications for Small Group Interaction." Advances in Group Processes 12:115-37.

Kao, Grace, and Kara Joyner. 2004. "Do Race and Ethnicity Matter among Friends? Activities among Interracial, Interethnic, and Intraethnic Adolescent Friends." The Sociological Quarterly 45:557-73. https://doi.org/10.1111/j.1533-8525.2004.tb02303.x.

Kreager, Derek A. 2008. “Guarded Borders: Adolescent Interracial Romance and Peer Trouble at School." Social Forces 87:887-910. https://doi.org/10.1353/sof .0.0128.

Kurdek, Lawrence A., and J. Patrick Schmitt. 1987. "Partner Homogamy in Married, Heterosexual Cohabiting, Gay and Lesbian Couples." The Journal of Sex Research 23:212-32. https://doi.org/10.1080/00224498709551358.

Lieberson, Stanley, and Mary C. Waters. 1988. From Many Strands: Ethnic and Racial Groups in Contemporary America. New York, NY: Russell Sage Foundation.

Loveman, Mara. 1999. “Is ‘Race' Essential?” American Sociological Review 64:891-98. https : //doi.org/10.2307/2657409.

Marsden, Peter V. 1987. “Core Discussion Networks of Americans." American Sociological Review 52:122-31. https://doi .org/10.2307/2095397.

Mays, Vickie M., Susan D. Cochran, and Sylvia Rhue. 1993. "The Impact of Perceived Discrimination on the Intimate Relationships of Black Lesbians." Journal of Homosexuality 25:1-14. https://doi.org/10.1300/J082v25n04_01.

McCall, Leslie. 2005. "The Complexity of Intersectionality." Signs: Journal of Women in Culture and Society 30:1771-800. https://doi .org/10 .1086/426800.

McPherson, Miller, Lynn Smith-Lovin, and James M. Cook. 2001. “Birds of a Feather: Homophily in Social Networks." Annual Review of Sociology 27:415-44. https://doi . org/10.1146/annurev.soc.27.1.415.

Nemeth, Charlan J. 1986. "Differential Contributions of Majority and Minority Influence." Psychological Review 93:23-32. https://doi .org/10.1037/0033-295X.93.1.23.

Peplau, Letitia Anne, Susan D. Cochran, and Vickie M. Mays. 1997. “A National Survey of the Intimate Relationships of African American Lesbians and Gay Men: A Look at Commitment, Satisfaction, Sexual Behavior, and HIV Disease." Pp. 11-38 in Ethnic and Cultural Diversity Among Lesbians and Gay Men, edited by B. Greene. Thousand Oaks, CA: Sage.

Perry, Samuel L. 2013. "Racial Composition of Social Settings, Interracial Friendship, and Whites' Attitudes toward Interracial Marriage." Social Science Journal 50:13-22. https : //doi.org/10.1016/j.soscij.2012.09.001.

Pew Research Center. 2015. "Multiracial in America: Proud, Diverse and Growing in Numbers." Retrieved June 6, 2016 (http://www.pewsocialtrends.org/2015/06/11/ multiracial-in-america/).

Qian, Zhenchao, and Daniel T. Lichter. 2007. "Social Boundaries and Marital Assimilation: Interpreting Trends in Racial and Ethnic Intermarriage." American Sociological Review 72:68-94. https://doi .org/10.1177/000312240707200104.

Robinson, Brandon Andrew. 2015. "'Personal Preference' As the New Racism: Gay Desire and Racial Cleansing in Cyberspace." Sociology of Race and Ethnicity 1:317-30. https : //doi.org/10.1177/2332649214546870.

Rockquemore, Kerry Ann, and David L. Brunsma. 2008. Beyond Black: Biracial Identity in America. 2nd ed. Lanham, MD: Rowman and Littlefield.

Romano, Renee C. 2003. Race Mixing: Black-White Marriage in Postwar America. Cambridge, MA: Harvard University Press. 
Root, Maria P. P. 2001. Love's Revolution: Interracial Marriage. Philadelphia, PA: Temple University Press.

Rosenfeld, Michael J. 2007. The Age of Independence: Interracial Unions, Same-Sex Unions, and the Changing American Family. Cambridge, MA: Harvard University Press.

Rosenfeld, Michael J., and Byung-Soo Kim. 2005. "The Independence of Young Adults and the Rise of Interracial and Same-Sex Unions." American Sociological Review 70:541-62. https://doi.org/10.1177/000312240507000401.

Savin-Williams, Ritch C., and Geoffrey L. Ream. 2007. "Prevalence and Stability of Sexual Orientation Components during Adolescence and Young Adulthood." Archives of Sexual Behavior 36:385-94. https : //doi .org/10.1007/s10508-006-9088-5.

Schnoor, Randal F., and Morton Weinfeld. 2005. "Seeking a Mate: Inter-group Partnership among Gay Jewish Men." Canadian Ethnic Studies 37:21-39.

Schwartz, Christine R., and Nikki L. Graf. 2009. "Assortative Matching among Same-Sex and Different-Sex Couples in the United States, 1990-2000." Demographic Research 21:843-78. https://doi .org/10.4054/DemRes.2009.21.28.

Sherrod, Drury, and Peter M. Nardi. 1994. "Friendship in the Lives of Gay Men and Lesbians." Journal of Social and Personal Relationships 11:185-99. https://doi.org/10. $1177 / 0265407594112002$.

Simmel, Georg. 1955. Conflict and The Web of Group Affiliations. New York, NY: Free Press.

Snipp, C. Matthew. 2003. "Racial Measurement in the American Census: Past Practices and Implications for the Future." Annual Review of Sociology 29:563-88. https : //doi . org/10 . 1146/annurev.soc.29.010202.100006.

Stanley, Jeanne L. 1996. “The Lesbian's Experience of Friendship." Pp. 39-59 in Lesbian Friendships, edited by J. S. Weinstock and E. D. Rothblum. New York, NY: New York University Press.

Surra, Catherine A., and Robert M. Milardo. 1991. "The Social Psychological Context of Developing Relationships: Interactive Psychological Networks." Pp. 1-36 in Advances in Personal Relationships, edited by W. H. Jones and D. Perlman. London, UK: Jessica Kingsley.

Tajfel, Henri. 1981. Human Groups and Social Categories. Cambridge, UK: Cambridge University Press.

Vaquera, Elizabeth, and Grace Kao. 2005. "Private and Public Displays of Affection among Interracial and Intra-racial Adolescent Couples." Social Science Quarterly 86:484-508. https://doi.org/10.1111/j.0038-4941.2005.00314.x.

Wang, Wendy. 2012. The Rise of Intermarriage: Rates, Characteristics Vary by Race and Gender. Washington, DC: Pew Research Center.

Wimmer, Andreas. 2013. Ethnic Boundary Making: Institutions, Power, Networks. New York, NY: Oxford University Press. https ://doi.org/10.1093/acprof : oso/9780199927371. 001.0001.

Wimmer, Andreas. 2015. "Race-Centrism: A Critique and a Research Agenda." Ethnic and Racial Studies 38:2186-205. https://doi .org/10.1080/01419870.2015.1058510.

Winant, Howard. 2015. "Race, Ethnicity and Social Science." Ethnic and Racial Studies 38:2176-85. https://doi.org/10.1080/01419870.2015.1058514.

Yancey, George. 2002. "Who Interracially Dates: An Examination of the Characteristics of Those Who Have Interracially Dated." Journal of Comparative Family Studies 33:179-90. 
Acknowledgments: The authors would like to acknowledge the valuable feedback provided by Monica McDermott, Michael Rosenfeld, Morris Zelditch, Jr., Tomás Jiménez, and Louis Mittel. Adam Horowitz and Charles Gomez made equivalently consequential contributions to this article, and authorship should be considered equal.

Adam L. Horowitz: The Edmond J. Safra Center for Ethics, Tel Aviv University, and Center for Comparative Studies in Race and Ethnicity, Stanford University.

E-mail: ahorowitz@stanford.edu.

Charles J. Gomez: Department of Sociology, Queens College, City University of New York. E-mail: charles.gomez@qc.cuny.edu.

\section{Errata: February 2019}

This article has been updated after a reader discovered and brought to the authors' attention a coding error with a control variable. Add Health codes two responses for declining to report income as 9999998 and 9999996. In the original analyses, these responses were not treated as missing. This authors have corrected the error and rerun the analyses, which are presented in the current version.

The most consequential results of this correction are as follows:

- The number of respondents in the analytical sample changed from 10,721 to 10,281 (p. 674)

- The descriptive statistics in Table 1 have changed due to the change in sample size. In addition, due to the recoding of income for some respondents to missing, the descriptive statistics for income at the bottom of the table have changed.

- The correlations reported in Table 2 have changed.

- Point estimates for coefficients and standard errors for the models reported in Table 3-6 have changed. These changes generally do not involve changes in statistical significance, and are generally not consequential for the interpretations offered, with the following exceptions:

- In Table 5, the effect of "GLB" in the "All other races" column is no longer significant at the $\mathrm{p}<.05$ letter. As a result, the text on p. 679 has been changed to say "GLBs are estimated to select four [previously: five] of six friendship network composition categories over 'all your race' at significantly higher rates than are heterosexuals."

- In Table 6, the effect of "Less than High School" in the "Almost all other races" is no longer statistically significant.

The originally published version of the paper is available at the journal's website. 